\title{
Dendritic Pathology in Prion Disease Starts at the Synaptic Spine
}

\author{
Martin Fuhrmann, Gerda Mitteregger, Hans Kretzschmar, and Jochen Herms \\ Center of Neuropathology and Prion Research, Ludwig Maximilians University, 81377 Munich, Germany
}

\begin{abstract}
Spine loss represents a common hallmark of neurodegenerative diseases. However, little is known about the underlying mechanisms, especially the relationship between spine elimination and neuritic destruction. We imaged cortical dendrites throughout a neurodegenerative disease using scrapie in mice as a model. Two-photon in vivo imaging over 2 months revealed a linear decrease of spine density. Interestingly, only persistent spines (lifetime $\geq 8 \mathrm{~d}$ ) disappeared, whereas the density of transient spines (lifetime $\leq 4 \mathrm{~d}$ ) was unaffected. Before spine loss, dendritic varicosities emerged preferentially at sites where spines protrude from the dendrite. These results implicate that the location where the spine protrudes from the dendrite may be particularly vulnerable and that dendritic varicosities may actually cause spine loss.
\end{abstract}

Key words: structural plasticity; spine; dendrite; prion; somatosensory cortex; two-photon

\section{Introduction}

The development of long-term in vivo imaging techniques enabled the study of structural plasticity of single synapses over extended periods of time up to one year or longer in living animals (Grutzendler et al., 2002; Trachtenberg et al., 2002; Holtmaat et al., 2005; Zuo et al., 2005; Majewska et al., 2006). Spines represent the smallest structural unit and are therefore of major interest to understanding the remodeling of neuronal circuits. These doorknob-shaped small protrusions from the dendritic shaft form the postsynaptic part of the majority of excitatory synapses in the cerebral cortex. Induction of LTP in organotypic slices leads to the formation of new spines in stimulated regions, although random elimination occurs throughout the whole slice (Engert and Bonhoeffer, 1999). Conversely, induction of LTD in the hippocampus causes spine shrinkage and retraction (Nagerl et al., 2004; Zhou et al., 2004). Spines are not only formed in response to activity, but their synaptic strength is also reflected in their size, as the spine volume is proportional to the AMPA receptor (AMPAR) content and the area of the postsynaptic density (Harris and Stevens, 1989; Nusser et al., 1998; Kharazia and Weinberg, 1999; Takumi et al., 1999). Long-term in vivo imaging in the neocortex has revealed two groups of spines: transient spines that appear and disappear over short time periods within days, and persistent spines that are long lasting, possibly stable throughout the entire life span (Grutzendler et al., 2002; Trachtenberg et al., 2002; Holtmaat et al., 2005). Transient spines are more abundant in the developing cortex, whereas the number of persistent spines increases during adulthood (Holtmaat et al.,

Received Nov. 22, 2006; revised April 17, 2007; accepted April 21, 2007.

This work was supported by the Bayerische Forschungsverbund ForPrion and the European Network of Excellence NeuroPrion. We thank Fritjof Helmchen for initial introduction to deep-tissue two-photon microscopy.

Correspondence should be addressed to Dr. Jochen Herms, Center of Neuropathology and Prion Research, Ludwig Maximilians University Munich, 81377 Munich, Germany. E-mail: Jochen.Herms@med.uni-muenchen.de. D0I:10.1523/JNEUROSCI.5062-06.2007

Copyright $\odot 2007$ Society for Neuroscience $\quad$ 0270-6474/07/276224-10\$15.00/0
2005), indicating that neuronal circuits continue to stabilize even in the adult brain. Nevertheless the adult brain still retains the capability of remodeling, because transient spines are still present.

Many results have been obtained regarding neuronal circuit plasticity in healthy animals. However, it has remained unclear what happens to cortical circuits and spine stability during neurodegenerative diseases like tauopathies, synucleinopathies, or prion diseases. This is an important issue because more and more evidence is accumulating supporting the notion that synaptic failure is the earliest manifestation of those diseases (Selkoe, 2002; Yoshiyama et al., 2007).

Prion diseases are fatal transmissible diseases that affect several species, including humans. The hallmark pathological features of these diseases are spongiform degeneration of the brain accompanied by extensive neuronal loss, synaptic alterations, astrogliosis, and cerebral accumulation of a misfolded and protease-resistant form of the prion protein, termed $\operatorname{PrP}^{\text {res }}$ or $\mathrm{PrP}^{\mathrm{Sc}}$ (Prusiner, 1998). $\mathrm{PrP}^{\mathrm{Sc}}$ deposition precedes neuronal death, but there are synaptic and dendritic alterations that are supposed to precede neuronal apoptosis by considerable time (Jeffrey et al., 2000). Dendritic abnormalities such as the emergence of varicosities and a decrease in dendritic spines have been well described in the terminal stage of different scrapie models (Hogan et al., 1987; Johnston et al., 1997; Belichenko et al., 2000; Jeffrey et al., 2000) as well as in humans suffering from Creutzfeldt-Jakob disease (Landis et al., 1981). More recently it has been suggested that synaptic dysfunction and loss is an early and pivotal step in the neuropathogenesis of prion disease (Cunningham et al., 2003; Ishikura et al., 2005); however, a detailed analysis of the spine pathology throughout the course of the disease is lacking. For example, it is unclear which class of spines is preferentially lost, transient or persistent spines. Does the spine loss correlate with the emergence of neurological symptoms and does it represent the basis for the onset of symptoms? Using the 
cranial window technique (Trachtenberg et al., 2002; Holtmaat et al., 2005) and 4-d-interval two-photon in vivo imaging over a period of up to 2 months, we aimed to analyze the kinetics of spine gain and loss during prion disease.

\section{Materials and Methods}

Infection with prions. The animal experiments were in accordance with animal protection standards and were approved by the government of Upper Bavaria (protocol number 209.1/211-2531-67/04). Heterozygous transgenic 8-week-old mice of the Thy-1 YFP-H line on a C57BL/6 background (Feng et al., 2000) (The Jackson Laboratory, Bar Harbor, ME) were inoculated intracerebrally with the prion strain RML (Rocky Mountain Laboratory, Ft. Collins, CO) using a dose of $30 \mu \mathrm{l}$ of $10 \%$ brain homogenate in sterile PBS. Inoculation was performed with a Luer lock system (catalog \#807.001C; Robert Helwig, Berlin, Germany). In brief, the needle (length, $0.4 \mathrm{~mm}$ ) was inserted into the cranial fissure between bregma and lambda, $2 \mathrm{~mm}$ caudal from bregma. The needle tip reached the basal ganglia, where the inoculation volume was injected. The laterimaged right somatosensory cortex remained completely unaffected by this procedure. Diethylether was used as an anesthetic. After inoculation, mice were returned to their cages and kept under standard animal facility conditions until the preparation of the cranial window. To check for possible influences of the inoculation procedure and of the repetitive in vivo imaging, three different groups of control mice were analyzed: age matched mock-inoculated YFP-H animals $(n=3)$ that obtained brain homogenate from noninfected donors, YFP-H $\times$ PrP\% mice $(n=2)$ inoculated with $10 \%$ RML, and noninfected YFP-H animals $(n=2)$ that received no treatment. As expected, mock-inoculated YFP-H animals remained healthy and $\mathrm{YFP}-\mathrm{H} \times \mathrm{PrP} \%$ animals were resistant to scrapie infection. Acute imaging of $\mathrm{YFP}-\mathrm{H} \times \mathrm{PrP} \%$ mice at 210 postinfection (dpi) over 120 min with 15 min imaging intervals revealed stable dendritic spines and no change in dendritic integrity. The spine density of these mice at 210 dpi was comparable with age-matched noninfected controls (supplemental Fig. $1 A-C$, available at www.jneurosci.org as supplemental material). Additionally, imaging of a RML-inoculated YFP-H $\times$ PrP\% mouse from 99 to 133 dpi revealed no signs of photoinduced damage and spine density was found to be unaffected (supplemental Fig. $1 D, E$, available at www.jneurosci.org as supplemental material). Similar results have been obtained in mock-inoculated mice (data not shown). Moreover comparing spine density, daily turnover ratio (dTOR), and acute spine stability in the three control groups revealed no significant difference (data not shown). These control experiments indicate that the inoculation procedure itself does not result in enhanced sensitivity of the cerebral cortex to photoinduced damage. All control data presented in Figures 1-5 are based on the analysis of noninfected YFP-H animals.

Surgery. A cranial window over the right cortical hemisphere was surgically implanted. The animals were anesthetized with an intraperitoneal dose of ketamine/xylazine $(0.13 / 0.01 \mathrm{mg} / \mathrm{g}$ body weight). Additionally, a small dose of dexamethasone $(0.02 \mathrm{ml}$ at $4 \mathrm{mg} / \mathrm{ml})$ was intraperitoneally administered immediately before surgery (Holtmaat et al., 2005). An 8 $\mathrm{mm}$ diameter circular part of the skin over the right parietal skull was removed. The periosteum was scraped away with a scalpel. Subsequently, a circular piece of the skull over the somatosensory cortex $(4 \mathrm{~mm}$ in diameter) was removed using a dental drill (XL-30W; Osada, Los Angles, $\mathrm{CA})$. Special care was taken to leave the underlying dura intact. The dura was covered with a thin layer of 1.5\% low-melt agarose (catalog \#A9793; Sigma, St. Louis, MO) in HEPES-buffered saline containing (in mM) 135 $\mathrm{NaCl}, 5.4 \mathrm{KCl}, 1 \mathrm{MgCl}_{2}, 1.8 \mathrm{CaCl}_{2}$ and $5 \mathrm{HEPES}$. Immediately, a round coverslip (5 mm diameter) was glued to the skull using dental acrylic (Cyano-Veneer fast; Heinrich Schein Dental Depot, Munich, Germany) to close the agarose-filled craniotomy. A small metal bar, containing a hole for a screw, was glued next to the coverslip. The metal bar allowed repositioning of the mouse during subsequent imaging sessions. Mice received a subcutaneous analgesic dose of carprophen (Rimadyl; Pfizer, New York, NY) for $3 \mathrm{~d}(5 \mathrm{mg} / \mathrm{kg}$, s.c.). Imaging began after an $8-12 \mathrm{~d}$ rest period. For acute two-photon in vivo imaging experiments lasting for $3-4 \mathrm{~h}$, the anesthetic urethane (1-2 mg/kg, i.p.; catalog \#U-2005; Sigma) was used instead of ketamine/xylazine. The mice were killed at the end of the experiment.

Imaging. Two-photon imaging was performed using an upright Zeiss (Jena, Germany) Axioskop 2Fs mot LSM510Meta/NLO setup, equipped with a MaiTai two-photon laser (Spectra Physics, Darmstadt, Germany). The MaiTai Ti:Saphir laser exhibited a bandwidth of 710-920 nm and was pumped by a $10 \mathrm{~W}$ solid-state laser (Millenia X; Spectra Physics). For imaging sessions, the wavelength of the two-photon laser was set to 880 $\mathrm{nm}$ to excite yellow fluorscent protein (YFP). For detection of epifluorescence, generated by two-photon excitation, the setup contained two non-descanned detectors with large aperture detection optics provided by Zeiss. The standard microscopy table was removed and replaced by a custom-made table to allow repeated positioning of a living mouse under the microscope. During chronic experiments, mice were anesthetized by an intraperitoneal injection of ketamine/xylazine (75\% of the surgical dose, $0.01 / 0.0075 \mathrm{mg} / \mathrm{kg}$ bodyweight). Imaging sessions lasted for 60 min. A Zeiss $40 \times$ water-immersion objective $(0.8$ numerical aperture $)$ was used to acquire image stacks of various sizes (50-700 $\mu \mathrm{m}$ depth) (see supplemental material, available at www.jneurosci.org) with $1 \mu \mathrm{m}$ $z$-resolution and $512 \times 512$ pixels per image frame $(0.15 \mu \mathrm{m} /$ pixel $)$. Care was taken to ensure similar fluorescence levels in space and time. For Image acquisition, the Zeiss LSM510 Rel3.2 software was used. Apical dendritic tufts in layer 1-2 of layer 5 neurons of the somatosensory cortex were imaged over time periods ranging from $3 \mathrm{~h}$ to 2 months. Repositioning of the same dendritic element over time was achieved by orienting at vascular pattern and unique branch points of apical dendrites. Three to seven positions per mouse, containing several dendritic elements up to $300 \mu \mathrm{m}$ below the pial surface, were imaged over the indicated time periods.

Image processing and data analysis. Image processing and data analysis were performed using the Zeiss LSM510 3.2Rel software in combination with Microsoft (Seattle, WA) Excel. All figures contained in this article are three-dimensional projections of $z$-sections. Before projection, images were low-pass and median filtered. In some figures, distracting dendritic elements were removed from the figure (see Fig. $1 A, B$ ). Spines and dendritic varicosities were counted in $z$-stacks by manully scrolling through the $z$-stacks of subsequent time points of the same position. All clear protrusions emanating laterally from the dendritic shaft, regardless of apparent shape, were measured. Spines were counted as stable when they were found at the same place, not $>0.5 \mu \mathrm{m}$ away from the previous position. Lost spines were counted as lost when they consisted of $<4$ pixels and as gained when they consisted of $>4$ pixels in length protruding from the dendrite. This scoring method has already been used successfully (Holtmaat et al., 2005). Because the $z$-axis resolution of twophoton microscopy is insufficiently low, only protrusions emanating from the dendrite in the $x-y$ direction were counted. Spines lasting for $4 \mathrm{~d}$ or less were classified as transient and spines lasting for $8 \mathrm{~d}$ or more were classified as persistent. Fractions of persistent $\left(F_{\mathrm{p}}\right)$ and transient $\left(F_{\mathrm{t}}\right)$ spines were calculated for each imaging day: $F_{\mathrm{p}}=N_{\text {persistent }} / N_{\text {total }} \times 100$; $F_{\mathrm{t}}=N_{\text {transient }} / N_{\text {total }} \times 100$, where $N_{\text {persistent }}$ and $N_{\text {transient }}$ are the number of spines that were classified persistent or transient for the analyzed day, and $N_{\text {total }}$ is the number of all present spines on the analyzed day. Fractions of gained $\left(F_{\text {gained }}\right)$ and lost $\left(F_{\text {lost }}\right)$ spines were calculated for each imaging day: $F_{\text {gained }}=N_{\text {gained }} / N_{\text {total }} / I_{\mathrm{t}} ; F_{\text {lost }}=N_{\text {lost }} / N_{\text {present }} / I_{\mathrm{t}}$, where $N_{\text {gained }}$ and $N_{\text {lost }}$ represent the number of gained and lost spines from one to the other imaging session, $N_{\text {total }}$ the number of present spines on the analyzed day, $N_{\text {present }}$ the number of spines present at the previous imaging session, and $I_{\mathrm{t}}$ the number of days of the imaging interval.

Dendritic varicosities were similarly analyzed. A dendritic varicosity was defined as the swelling of a dendrite to 1.5 -fold of its adjacent diameter Stable varicosities were counted as stable when they were found not $>0.5 \mu \mathrm{m}$ away from their previous position and lost when the diameter of the varicosity decreased to $<1.5$-fold of the adjacent diameter. Scoring of dendritic spines and varicosities was performed in a blind manner by an experimenter without any knowledge of the experimental conditions. Turnover ratios representing the gain and loss of spines/varicosities from day to day were calculated as dTOR $=\left(N_{\text {gained }}+N_{\text {lost }}\right) /\left(2 \times N_{\text {total }}\right) / I_{\text {t }}$, where $N_{\text {gained }}$ is the number of gained spines/varicosities, $N_{\text {lost }}$ is the number of lost spines/varicosities, $N_{\text {total }}$ is the number of all apparent 
spines/varicosities at a time point, and $I_{\mathrm{t}}$ is the number of days between subsequent imaging sessions. Spine and varicosity densities refer to the dendrite length in $\mu \mathrm{m}$ from which they protrude, divided by $I_{\mathrm{t}}$.

Statistics. All data are presented as mean \pm SEM if not otherwise stated. To test significance, unpaired Student's $t$ test was performed and differences were considered statistically significant if $p<0.05$.

To test whether the observed percentage of spine-gained varicosities was different from the random case, a binomial test was conducted as follows. Assuming a random distribution of spines and varicosities with a mean spine density of $0.4 \pm 0.05 \mu \mathrm{m}^{-1}$, a mean spine-shaft diameter of $0.5 \pm 0.02 \mu \mathrm{m}^{-1}$, a mean density of varicosities of $0.1 \pm 0.01 \mu \mathrm{m}^{-1}$, and a mean varicosity diameter of $1.5 \pm 0.05 \mu \mathrm{m}^{-1}$, the theoretical probability for a spine-gained varicosity at any place of the dendrite is $3 \%$. Because only places with varicosities and not random places on the dendrite were analyzed, we divided the probability for a spine-gained varicosity at a random place (3\%) by the probability for a varicosity (15\%), which results in a probability of a spine-gained varicosity at places with varicosities of $20 \%\left(p_{0}\right)$. If $n$ is the number of varicosities and $m$ the number of spine-gained varicosities, the null hypothesis that the observed probability is equal or smaller than $p_{0}=0.2$ can be rejected to the level of significance $\alpha$, if $\left(m-n \times p_{0}\right) /\left(n \times p_{0} \times\left(1-p_{0}\right)\right)^{0.5}>u_{1-\alpha / 2}$. The term $u$ represents a quantile of the normal distribution.

\section{Results}

Here, we applied two-photon in vivo imaging in a mouse model of prion disease to analyze the structural plasticity of dendritic spines in a chronic neurodegenerative disease. Dendritic pathology is one of the characteristic hallmarks of neurodegenerative diseases like prion disease or more common diseases like the tauopathies or synucleinopathies (Fiala et al., 2002). Previous studies indicate that the pathology at dendritic spines, at least in tauopathies, may be the earliest manifestations of neurodegeneration (Yoshiyama et al., 2007). Therefore it is important to analyze the kinetics of structural spine plasticity and structural changes at the dendrite as well as possible regulatory phenomena throughout a chronic neurodegenerative disease. We chose the scrapie model in mice because it resembles a human neurodegenerative disease better than all other so far established models of Alzheimer's or Parkinson's disease. After different incubation times ranging from the presymptomatic [from 90 to $120 \mathrm{~d}$ postinfection (dpi)] to the symptomatic (from $120-160 \mathrm{dpi}$ ) phase, cranial windows were implanted above the right somatosensory cortex, enabling repeated imaging of identical dendritic elements over time periods from $3 \mathrm{~h}$ to 2 months.

\section{Acute dendritic spine stability}

Mechanisms underlying short-term structural plasticity of spines have been successfully identified by in vitro studies (Tada and Sheng, 2006). LTP, for example, induces spine swelling, whereas LTD promotes spine shrinkage, both mediated by actin polymerization and depolymerization (Okamoto et al., 2004). To elucidate whether any short-term structural plasticity modifications occur, presymptomatic (100 dpi) and symptomatic (130 dpi) scrapie-infected mice were analyzed over a time period of $3 \mathrm{~h}$. Figure $1 A$ depicts typical spine and dendritic integrity at the presymptomatic phase of the disease examined by two-photon in vivo imaging. Compared with this, Figure $1 B$ shows spine and dendritic alterations associated with the symptomatic phase of prion disease (Fig. $1 B$ ). The spine density per dendrite length was significantly reduced in symptomatic compared with presymptomatic mice (Fig. $1 C)\left(100 \mathrm{dpi}, 0.4 \pm 0.05 \mu \mathrm{m}^{-1} ; 130 \mathrm{dpi}\right.$, $0.17 \pm 0.03 \mu \mathrm{m}^{-1} ; n=6$ animals; 3029 spines; $\left.p=0.017\right)$. In parallel to a decreased spine density in symptomatic mice, the mean dendritic diameter was also found to be decreased (Fig. $1 D$ ) (100 dpi, $1.1 \pm 0.03 \mu \mathrm{m} ; 130 \mathrm{dpi}, 0.64 \pm 0.04 \mu \mathrm{m} ; n=6$ animals;
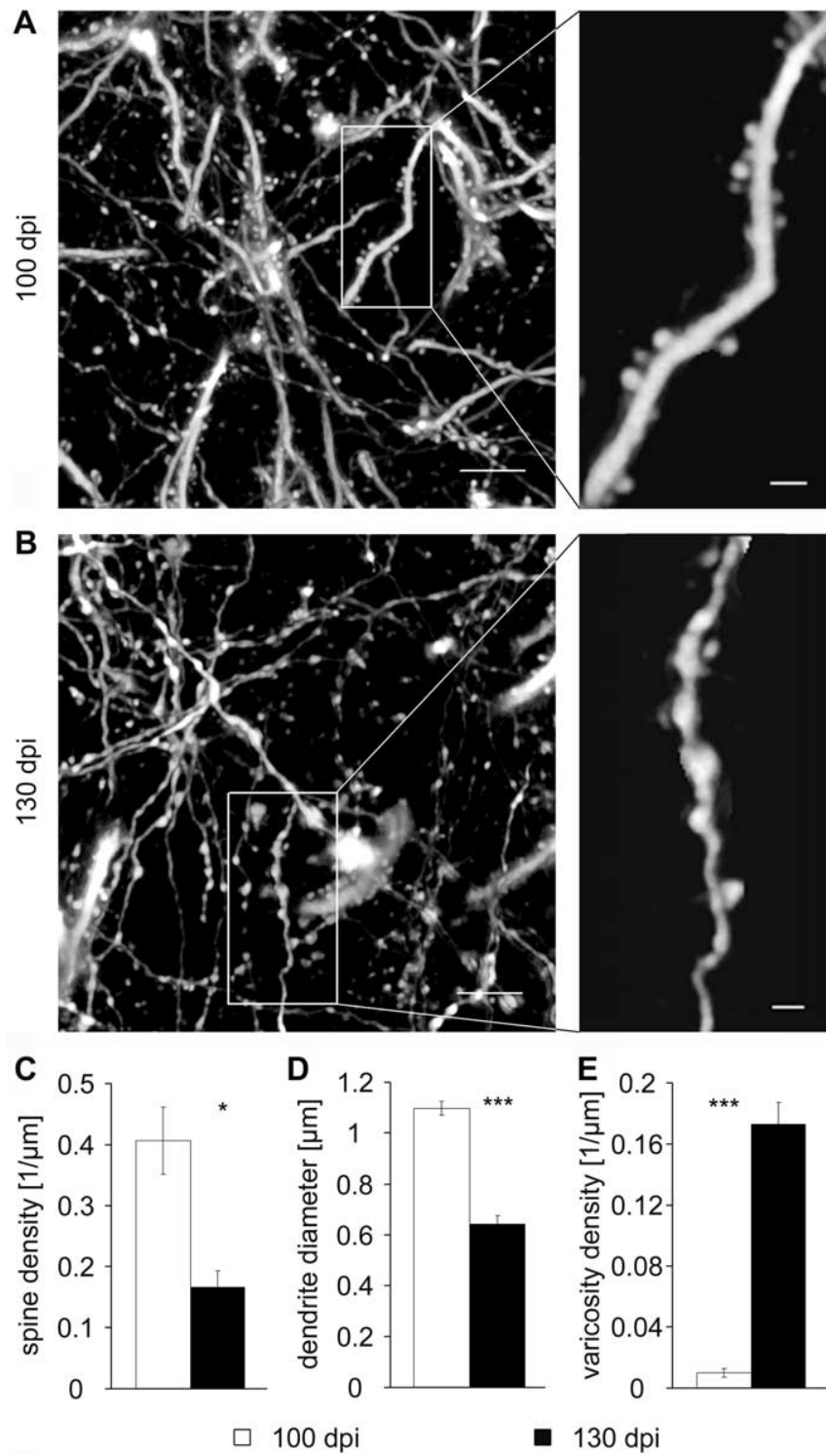

Figure 1. Typical spine and dendritic alterations of presymptomatic compared with symptomatic scrapie-infected mice. $\boldsymbol{A}, \boldsymbol{B}$, Representative images from two-photon in vivo imaging sessions of apical dendrites and adjacent spines of presymptomatic ( $100 \mathrm{dpi}$ ) and symptomatic (130 dpi) scrapie-infected Thy-1 YFP expressing mice. In contrast to the intact dendrites and unchanged spine density of presymptomatic mice, symptomatic mice exhibit spine loss and an increased number of dendritic swellings (varicosities). C, Mean spine density (1 per micrometer of dendrite length) is significantly reduced in symptomatic mice compared with presymptomatic mice $\left({ }^{*} p=0.017\right)$. $D$, Symptomatic scrapie-infected mice exhibited a reduced mean dendrite diameter (in micrometers) compared with presymptomatic mice $\left({ }^{* * *} p=9.9 \times 10^{-14}\right) . \boldsymbol{E}$, Dendrites of presymptomatic mice display fewer varicosities per dendrite length compared with symptomatic mice $\left({ }^{* * *} p=6.4 \times 10^{-23}\right)$. Scale bars: $\boldsymbol{A}, \boldsymbol{B}, 10 \mu \mathrm{m}$; insets, $2 \mu \mathrm{m}$.

49 dendrites; $\left.p=9.9 \times 10^{-14}\right)$. Only few dendritic varicosities were found in presymptomatic mice ( $100 \mathrm{dpi})$; in contrast to this, the density of varicosities per micrometer of dendrite was significantly increased in symptomatic mice (Fig. 1E) (100 dpi, $0.009 \pm 0.002 \mu \mathrm{m}^{-1} ; 130 \mathrm{dpi}, 0.17 \pm 0.01 \mu \mathrm{m}^{-1} ; n=6$ animals; 148 varicosities; $p=6.4 \times 10^{23}$ ).

Examination of identical dendrites and spines over a period of $3 \mathrm{~h}$ in vivo revealed insights into short-term plasticity. Spines, varicosities and apical dendrites remained unchanged in presymptomatic and symptomatic mice during this time period (Fig. 2A). Nearly $99 \%$ of spines were found to be stable over a 


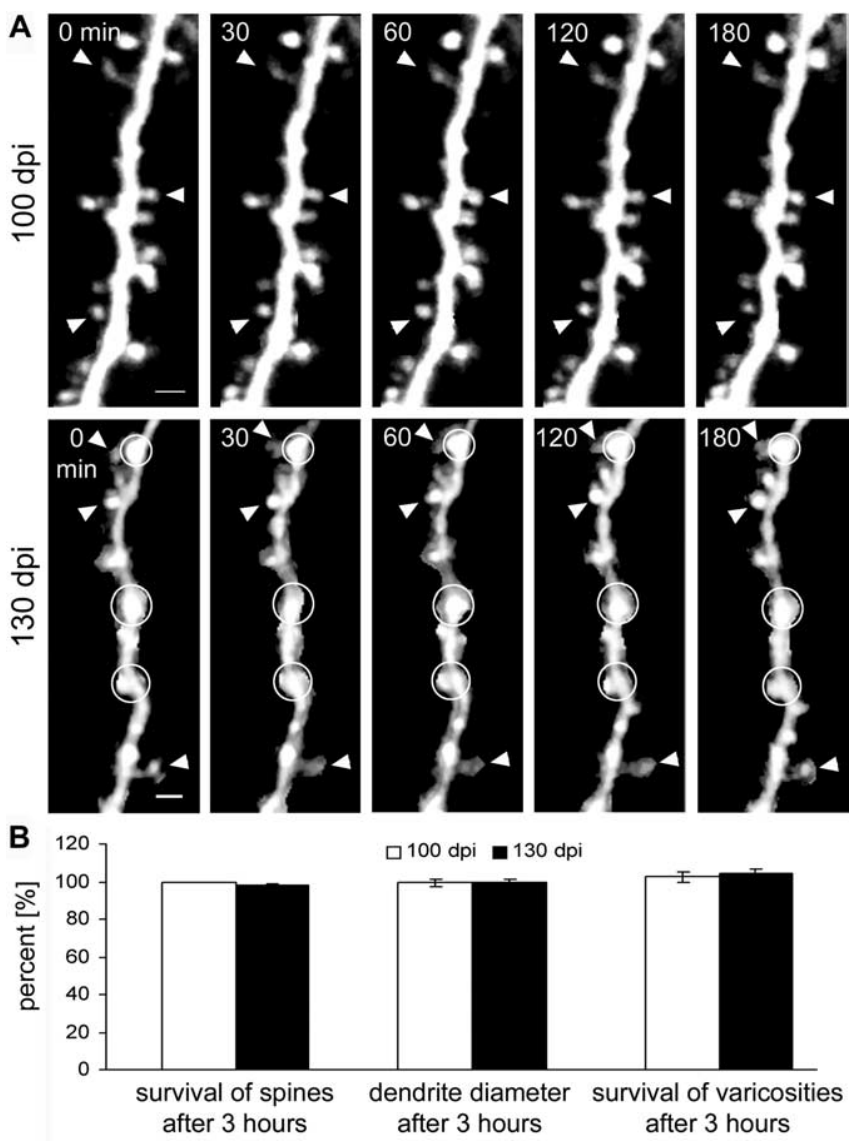

Figure 2. Spines and dendritic varicosities are stable over $3 \mathrm{~h}$ throughout the presymptomatic and symptomatic phases of the disease. $\boldsymbol{A}$, Repeated imaging of dendritic elements of scrapie-infected mice at 100 and $130 \mathrm{dpi}$. Note that spines (arrowheads) and varicosities (cir(les) are stable over the entire imaging period. $\boldsymbol{B}$, Spine number, dendrite diameter, and number of varicosities do not change within $3 \mathrm{~h}$ of imaging (spines, $p=0.4$; dendrite, $p=0.9$; varicosities, $p=0.9)$. Scale bars, $2 \mu \mathrm{m}$.

time period of $3 \mathrm{~h}$ in presymptomatic as well as in symptomatic mice (Fig. 2 B) (100 dpi, $99.4 \pm 0.2 \%$; 130 dpi, $98.0 \pm 0.4 \%$; $n=$ 6 animals; 6779 spines; $p=0.4$ ). Quantification of dendrite diameter in presymptomatic and symptomatic mice revealed stable dendritic diameters during imaging intervals of $3 \mathrm{~h}$ (Fig. 2 B) (100 dpi, $99.3 \pm 1.8 \%$ stable dendritic diameter; $130 \mathrm{dpi}, 99.8 \pm 1.6 \%$ stable dendritic diameter; $n=6$ animals; 40 dendrites; $p=0.9$ ). Dendritic varicosities were found to be stable over $3 \mathrm{~h}$ in presymptomatic and symptomatic scrapie-infected mice (Fig. 2 B) (100 dpi, $0-3 \mathrm{~h}, 103 \pm 2 \%$ stable varicosities; $130 \mathrm{dpi}, 0-3 \mathrm{~h}$, $104 \pm 3 \%$ stable varicosities; $n=6$ animals; 147 varicosities; $p=$ 0.7). Morphological changes like spine swelling or shrinkage as well as spine sprouting were not observed during $3 \mathrm{~h}$ imaging periods. These results lead to the conclusion that, although profound structural plasticity changes occur in scrapie-infected symptomatic animals, these alterations do not belong to the class of short term plasticity modifications that develop within hours.

\section{Spine gain precedes slow loss of dendritic spines}

During the first 2 months of development, a substantial proportion of spines is lost on apical dendrites of cortical layer 5 (L5) neurons independent of the cortical region (Holtmaat et al., 2005; Zuo et al., 2005). With increasing age, spines become more and more stable, lasting for over 18 months or maybe throughout a lifetime ( $>70 \%$ of all spines). What happens to these spines during a neurodegenerative disease? It has long been shown that spine densities decrease during Alzheimer's disease (Tsai et al., 2004; Spires and Hyman, 2004), Parkinson's disease (Patt et al., 1991), and prion disease (Hogan et al., 1981; Johnston et al., 1997; Brown et al., 2001). Ischemia leads to acute spine loss within hours (Zhang et al., 2005), whereas epilepsy and most forms of mental retardation, like prenatal infection, malnutrition, toxin exposure, and alcohol abuse result in permanent spine loss (Jiang et al., 1998; Fiala et al., 2002). Nevertheless the exact kinetics of spine elimination are not known. Therefore, the structural plasticity of dendrites and adjacent spines was quantified in scrapieinfected 5-month-old mice from the presymptomatic to the symptomatic phase of the disease. Two-photon in vivo imaging was performed in $4 \mathrm{~d}$ intervals to repeatedly image identical apical dendritic elements of cortical L5 neurons (Figs. 3, 4, 5). Spine density of presymptomatic mice $\left(0.35 \pm 0.04 \mu \mathrm{m}^{-1}\right.$ at $\left.100 \mathrm{dpi}\right)$ was comparable with spine density of age-matched noninfected control mice $\left(0.38 \pm 0.02 \mu \mathrm{m}^{-1}\right.$ at 5 months $)$ and to published values (0.29 $\pm 0.08 \mu \mathrm{m}^{-1} 6$ months) (Holtmaat et al., 2005). Individual spines were tracked over the whole imaging period, which allowed the identification of persistent and transient spines. To compare the current data with previously published results, analogous analysis criteria to those set by Holtmaat et al. (2005) were applied: individual spines that were present for at least $8 \mathrm{~d}$ were classified as persistent, whereas spines exhibiting a lifetime of $4 \mathrm{~d}$ or shorter were classified as transient. We proceeded equally with the quantification of dTORs that represent the fraction of daily gained and lost spines. Control mice exhibited stable spine densities and dTORs (Fig. $3 D, E$ ). dTORs appear to be lower compared with published values because the percent value was additionally normalized to a daily imaging interval by dividing the percent value by the number of days of the corresponding imaging interval. Mice infected with scrapie prions exhibited a constant decrease of spine density over time from values comparable with controls at the presymptomatic phase of the disease, to values of nearly total spine loss at the terminal stage (Fig. 3D). The progression of spine loss in scrapie-infected animals took place over several days to weeks with linear kinetics of $5.9 \pm 0.5$ spines $/ \mathrm{mm}$ per day (Fig. $3 D$ ), therein differing substantially from short-term plasticity modifications.

Already during the presymptomatic stage of the disease, scrapie-infected mice exhibited higher dTORs compared with controls (Fig. 3G) (100 dpi, $4 \pm 0.5 \%$; control, $2 \pm 0.2 \%$; $n=6$ animals; $p=0.02$ ). This effect resulted from increased spine loss in scrapie-infected mice compared with controls. Probably the image acquisition start point coincided with the beginning of increased spine-loss. This would explain why the spine-density at $96 \mathrm{dpi}$ is comparable with controls, and why the dTOR calculated $4 \mathrm{~d}$ later is already increased at $100 \mathrm{dpi}$. Alternatively, dendrites and spines in scrapie-infected mice were more prone to laserinduced damage. This seems less likely because, first, symptomatic scrapie-infected mice receiving a photon dose equivalent to the dose of all imaging sessions conducted over 2 months, administered by repeated 15-min-interval imaging over a period of $3 \mathrm{~h}$, exhibited no signs of photoinduced damage (Fig. 2A). Second, spine density of mice imaged only once at $130 \mathrm{dpi}$ was found to be significantly reduced compared with mice imaged once at $100 \mathrm{dpi}$ (Fig. 1C). Therefore, we favor the hypothesis that the beginning of spine loss coincided with the start of the image acquisition.

dTOR was found to increase substantially with the onset of the symptomatic phase of the disease beginning at 120 dpi (Fig. 3E). To investigate whether the observed dTOR increase during the symptomatic phase of the disease was caused by alterations in 
spine loss or spine gain, gained and lost spines were examined independently. Comparing the time course of the fraction of gained and lost spines revealed that the fraction of lost spines outweighed the fraction of gained spines throughout the examination period. Moreover, the fraction of lost spines exhibited a substantial increase beginning at $135 \mathrm{dpi}$, when the symptomatic phase had already begun (Fig. 3E). Surprisingly, the fraction of gained spines exhibited an increase around the beginning of the symptomatic phase (120 dpi) (Fig. 3F). Thus, the increase of dTOR at the beginning of the symptomatic phase resulted from an increase of the gained spine fraction rather than from an augmented fraction of lost spines. The raise of the gained spine fraction clearly preceded the increase of the lost spine fraction (Figs. $3 F, G$ ). These observations lead to the conclusion that, with the onset of the symptomatic phase of the disease (120 dpi), a critical time point of neurodegeneration is reached, when neurons react to increasing spine loss by enhanced formation of new spines. However, enhanced spine gain seems to be insufficient to cope with the progression of the disease. This result implicates that mechanisms regarding the development of new spines are not impaired.

Five independent studies calculated fractions of persistent and transient spines in different cortical areas (Grutzendler et al., 2002; Trachtenberg et al., 2002; Holtmaat et al., 2005; Zuo et al., 2005; Majewska et al., 2006). These studies agree on the point that in older animals ( $>3$ months) spines become more and more stable. Holtmaat et al. (2005) found the highest fractions of transient spines in the somatosensory and visual cortex that decreased with age, whereas the other studies found smaller fractions of transient and higher fractions of persistent spines. In this study, the pathological decrease of spines forced us to calculate transient and persistent spine fraction for every imaging day. Thus, the referenced imaging day was not the first day of imaging, but the last two imaging sessions before the day to be analyzed (imaging interval, $4 \mathrm{~d}$ ) (see Materials and Methods). In this way, those spines are also included that are gained and become stable during subsequent imaging sessions (Fig. 3C). Analyzing the density and fraction of persistent and transient spines over time in control and scrapie-infected mice revealed a constant density of persistent and transient spines in control mice (Table 1). Mice infected with scrapie prions exhibited a decrease of persistent spine density and fraction from the presymptomatic to the symptomatic phase of
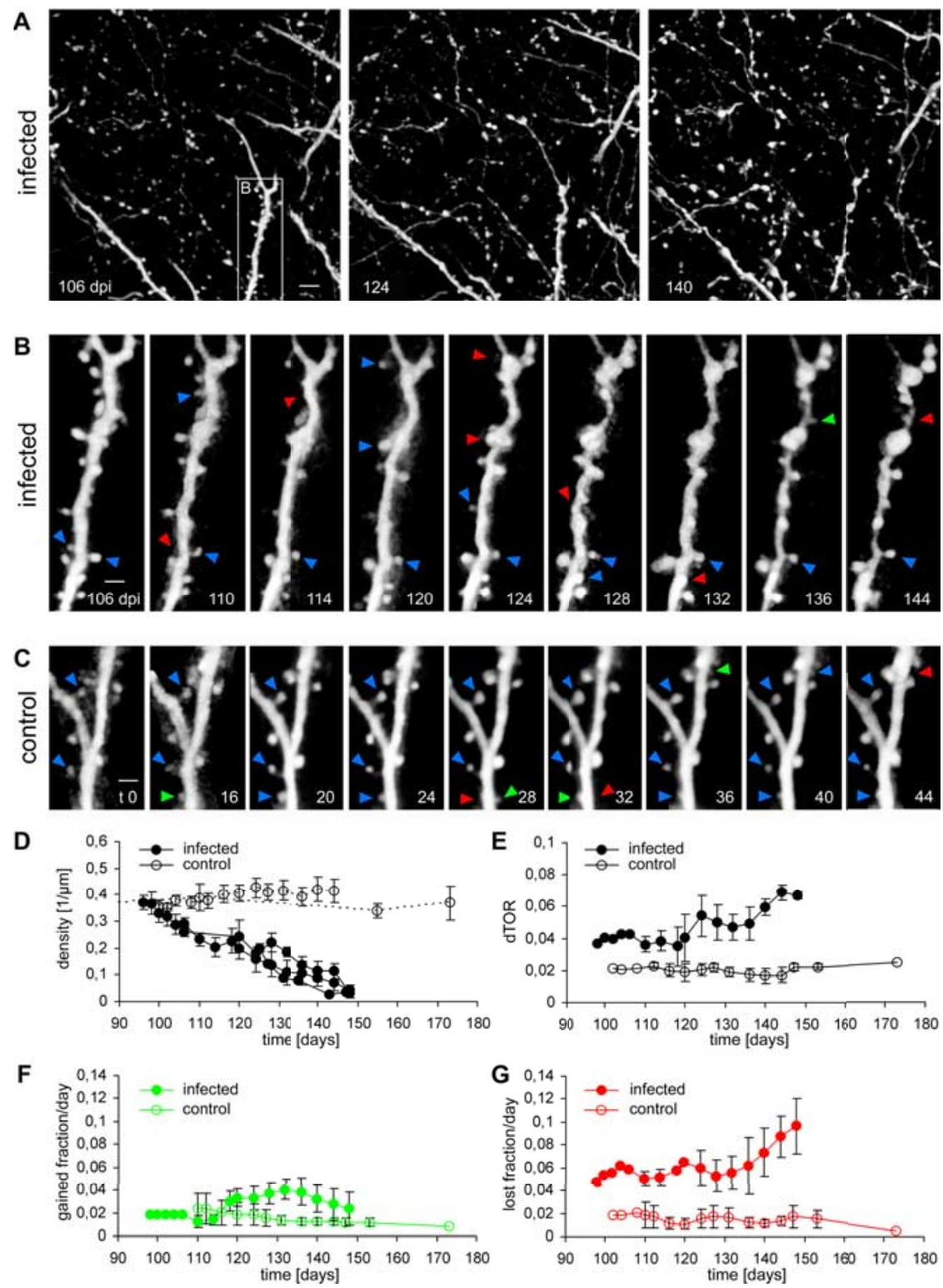

Figure 3. Kinetics of spine gain and loss of scrapie-infected and control mice from the presymptomatic to the symptomatic phase of prion disease. $\boldsymbol{A}$, Low-magnification time-lapse images of a dendritic arbor part in the somatosensory cortex of a scrapie-infected YFP-H animal from the presymptomatic to terminal phase. $\boldsymbol{B}$, Time series of a dendritic branch (from boxed region in $\boldsymbol{A}$ ). Blue arrows exemplarily indicate persistent spines, red arrows point at lost spines, and green arrows specify gained spines. Note that persistent spines are continuously lost during the symptomatic phase of the disease. Spine loss is not compensated by the gain of spines. $\boldsymbol{C}$, Time-lapse images of a dendritic branch of a control mouse imaged over a similar period ( $44 \mathrm{~d}$ ) as scrapieinfected mice. Most of the spines are persistent (blue arrows), and spine loss and gain are balanced. $D$, Spine densities of scrapieinfected (filled circles) and control (open circles) mice. Lines correspond to individual animals and circles represent imaging days. Time-point values represent mean spine densities of 5-8 independent dendritic branches. Whereas the spine density of control mice remained constant, scrapie-infected animals exhibited a constant decrease of spine density from the presymptomatic to terminal phase of the disease. $\boldsymbol{E}$, Mean daily spine turnover ratios of scrapie-infected (filled circles; $n=3$ animals) and control mice (open circles; $n=3$ animals). $\boldsymbol{F}$, Average gained spine fraction per day of scrapie-infected and control mice ( $n=3$ animals each). During the presymptomatic phase of the disease, spine-gain values of diseased mice are comparable with control animals. Accompanied by the onset of the symptomatic phase of disease at $120 \mathrm{dpi}$, scrapie-infected animals exhibit an increased fraction of gained spines. $\mathbf{G}$, Average lost spine fraction of scrapie-infected and control mice ( $n=3$ animals each). Already during the presymptomatic phase of the disease, scrapie-infected animals display a higher fraction of lost spines compared with controls. From $135 \mathrm{dpi}$ on, highly increased spine loss occurs. Note that in scrapie-infected animals, a period of increased spine gain (120-135 dpi; $\boldsymbol{F}$ ) precedes a period of increasing spine loss (135-150 dpi; $\boldsymbol{G})$. Scale bars: $\boldsymbol{A}, 5 \mu \mathrm{m} ; \boldsymbol{B}, \boldsymbol{C}, 2 \mu \mathrm{m}$.

disease (Table 1). Transient spine density remained constant, whereas the fraction of transient spines increased from the presymptomatic to the terminal phase of prion disease. This increase in the fraction of transient spines is a calculative phenom- 

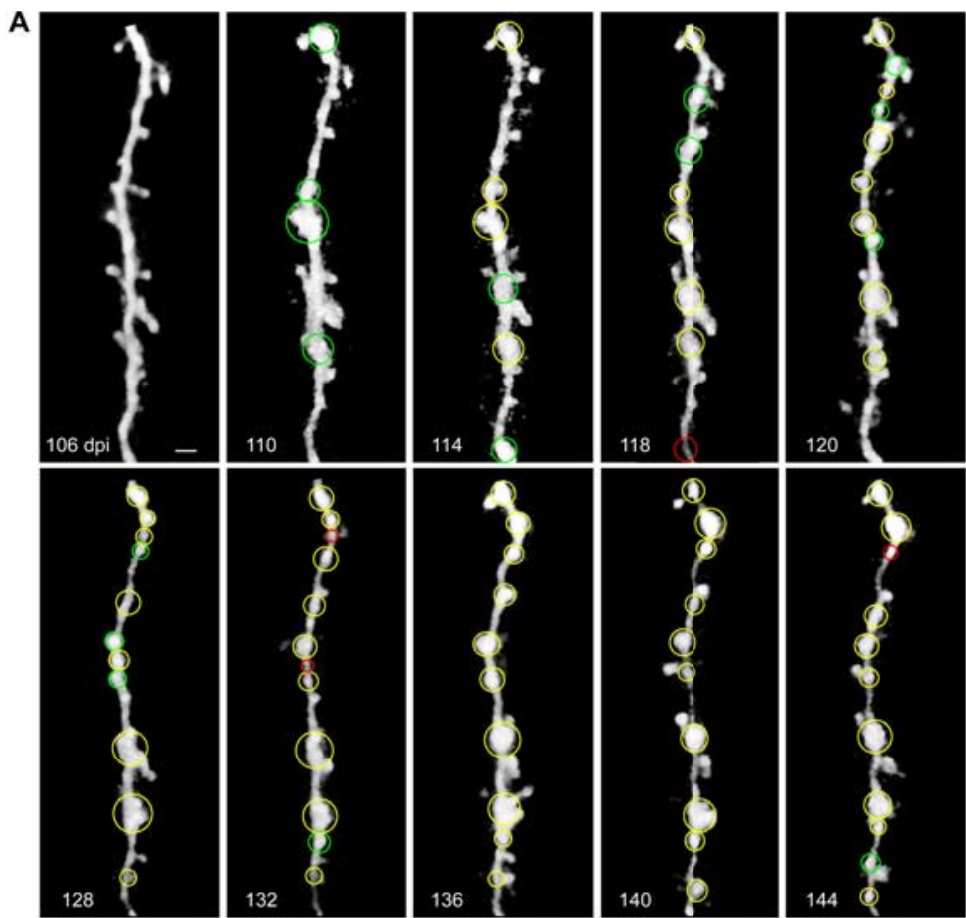

B

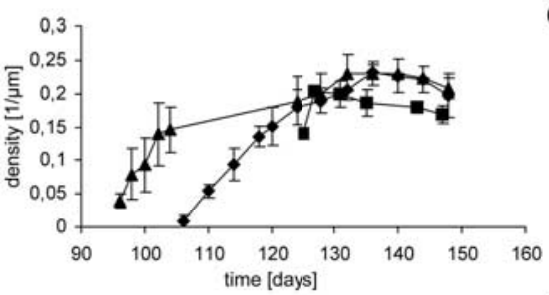

C 0,3
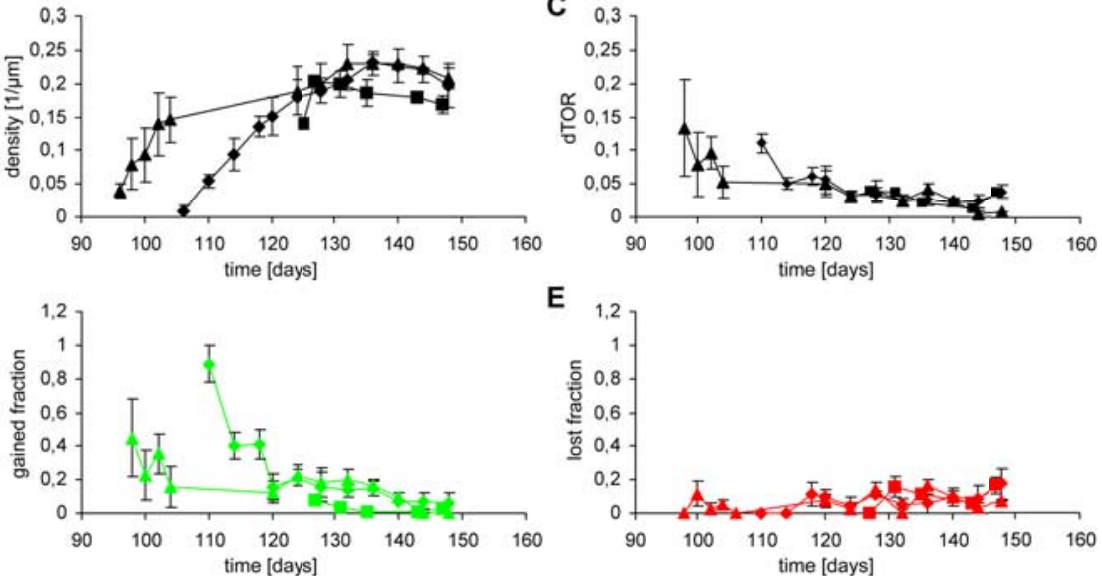

Figure 4. Structural plasticity of varicosities in scrapie-infected mice from the presymptomatic to the symptomatic phase of the disease. $\boldsymbol{A}$, Representative time-lapse images of a dendritic branch of a scrapie-infected YFP-H mouse. Green circles represent gained, yellow circles indicate persistent, and red circles point at lost varicosities. Note that a large number of varicosities were gained during the presymptomatic phase of the disease until $120 \mathrm{dpi}$. Of the gained varicosities, $90 \pm 2.7 \%$ persisted throughout the entire imaging period. Loss of varicosities was rarely observed. $\boldsymbol{B}$, Density of varicosities from the beginning of the presymptomatic to the end of the symptomatic phase of the disease. Lines correspond to individual animals and symbols represent imaging days. Time-point values represent mean densities of varicosities of 5-8 independent dendritic branches. Varicosity densities of scrapie-infected animals exhibited a constant increase from the presymptomatic to the symptomatic phase of the disease, reaching a plateau from $130 \mathrm{dpi}$ on. $\boldsymbol{C}$, Mean daily varicosity turnover ratios of scrapie-infected mice. $\boldsymbol{D}$, Average gained varicosity fraction of scrapie-infected mice. During the presymptomatic phase of disease, varicosity gain was greater than after the onset of the symptomatic phase at $120 \mathrm{dpi}$. $\boldsymbol{E}$, Average lost varicosity fraction per day of scrapie-infected mice. Varicosity loss remained constantly low throughout the entire imaging period. Scale bar, $2.5 \mu \mathrm{m}$.

enon, caused by a decrease in persistent spine density rather than to a real increase in transient spine density. The present study shows that especially persistent spine elimination occurs during the symptomatic phase of the disease from $120 \mathrm{dpi}$ on. Transient spines seem to be unaffected.

\section{Development of dendritic varicosities results in} dendritic beading

Another phenomenon often observed under neuropathological conditions is the swelling of dendritic shafts that is also referred to
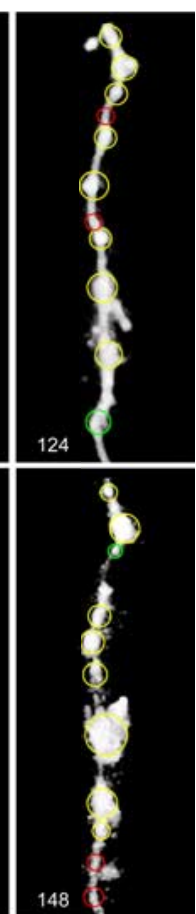

as dendritic varicosity. Dendritic varicosities appear like beads, which lead to the expression "dendritic beading." Varicosities occur rapidly under sublethal hypoxia, glutamate receptor activation, or excitotoxicity (Park et al., 1996; Hasbani et al., 2001). This process is often accompanied or followed by a thinning of dendritic shaft diameter (Spires et al., 2005). Additionally, axonal varicosities were found in close proximity to amyloid plaques in transgenic Alzheimer's disease mouse models (Tsai et al., 2004). To our knowledge, no data exists concerning the longterm kinetics of the structural plasticity of varicosities obtained by two-photon in vivo imaging. As mentioned above, the acute experiments of the present study revealed an increased density of varicosities in symptomatic scrapie-infected mice (Fig. $1 E$ ) (100 dpi, $0.009 \pm 0.002 \mu \mathrm{m}^{-1}$, $130 \mathrm{dpi}, 0.17 \pm 0.01 \mu \mathrm{m}^{-1} ; n=6$ animals; $\left.p=6.4 \times 10^{-23}\right)$, as well as a reduced dendritic shaft diameter (Fig. 1D) (100 dpi, $1.1 \pm 0.03 \mu \mathrm{m} ; 130 \mathrm{dpi}, 0.64 \pm 0.04 \mu \mathrm{m}$ $n=6$ animals; $\left.p=9.9 \times 10^{-14}\right)$. As for spines, long-term kinetics of parameters like varicosity density per micrometer, varicosity dTOR, transient and persistent varicosity density, and gained and lost varicosity fraction were investigated. Figure $4 \mathrm{~A}$ depicts time-lapse images of a representative dendritic branch showing the development of dendritic varicosities during the progression of prion disease. The density of varicosities per micrometer of dendrite increases with progression of the disease in scrapie-infected animals (Fig. $4 B)$. The density of dendritic varicosities considerably increases throughout the presymptomatic phase of the disease and reaches a plateau during the terminal phase. Of all varicosities gained during the imaging period, $61 \pm 5 \%$ were already present at $124 \mathrm{dpi}$. The gain of varicosities results in dendritic beading and leads to a thinning of the dendrite located between varicosities (Fig. 4A). Dendritic breakage was rarely observed and coincided with late terminal disease. Daily turnover ratios of varicosities $\left(\mathrm{dTOR}_{\mathrm{V}}\right)$ were elevated during the presymptomatic phase and remained constant throughout the symptomatic phase of the disease (Fig. 4C). The daily fraction of lost varicosities was small from the beginning to the end of the imaging period in diseased animals, whereas the fraction of daily gained varicosities decreased from very high values during the presymptomatic phase of the disease to values comparable with the daily lost varicosity fraction (Figs. $4 D, E$ ). Of gained varicosities, $90 \pm 2.7 \%$ persisted throughout the entire imaging period whereas only a small proportion of varicosities was transient (persistent: stable for 8 or more days; transient: stable for 4 or less days). This indicates that, after a dynamic gain of varicosities 
during the presymptomatic phase of prion disease, varicosities become persistent and last throughout the whole symptomatic phase of the disease.

\section{Spines are lost where varicosities are gained}

In order find out whether there exists a correlation between the onset of varicosities and the loss of spines, two additional parameters were analyzed. First, we quantified the number of varicosities that were gained at a dendritic position where a spine protruded from the dendrite (spinegained varicosities). Second, the number of spines that were lost at a position where a dendritic varicosity existed (varicositylost spines) was determined. Additionally, we counted the amount of varicosities gained at dendritic positions, where no spine emanated (dendrite-gained varicosities). Figure 5, $A$ and $B$, shows a representative time series of dendritic spines and varicosities during the progression of prion disease. Dendritic varicosities, either spine- or dendrite-gained, mainly emerged during the presymptomatic phase of the disease $(61 \pm 5 \% ; n=3)$. Interestingly, $72 \pm 4 \%$ of all varicosities were gained at dendritic sites, where spines protruded (spine-gained varicosities). Moreover, $75 \pm 6 \%$ of the total number of spine-gained varicosities emerged during the presymptomatic phase of the disease. The high spine density during the presymptomatic phase required to test if the observed percentage of spine-gained varicosities was different from the random case. Conducting a binomial test (see Material and Methods, Statistics), the observed percentage of $75 \pm 6 \%$ was significantly different from the calculated random case of $20 \%(p<$ $0.001 ; n=3$ mice). This observation is underlined by the time course of the density of spine-gained varicosities (Fig. 5C). The density of spine-gained varicosities decreased from $0.04 \pm 0.007 \mu \mathrm{m}^{-1}$ during the presymptomatic phase to $0.004 \pm$ $0.002 \mu \mathrm{m}^{-1}$ throughout the symptomatic phase of the disease $(n=3$ animals; $p=$ $\left.3.4 \times 10^{-4}\right)$. The density of dendrite-gained varicosities ranged around $0.01 \pm 0.003 \mu \mathrm{m}^{-1}$ during the presymptomatic phase of the disease and increased significantly after the onset of the symptomatic phase of the disease ( $136 \mathrm{dpi}, 0.03 \pm 0.005 \mu \mathrm{m}^{-1} ; n=3$; $\left.p=3.8 \times 10^{-3}\right)$ (Fig. $\left.5 D\right)$. Quantifying the density of varicositylost spines revealed values around $0.009 \pm 0.005 \mu \mathrm{m}^{-1}$ during the presymptomatic phase of the disease. With the onset of the symptomatic phase, the density of spines that are lost at varicosities peaked at $\sim 130 \mathrm{dpi}\left(0.04 \pm 0.007 \mu^{-1}\right)$ and decreased again during the terminal phase of disease (Fig. 5E) (presymptomatic, $0.009 \pm 0.005 \mu \mathrm{m}^{-1}$; symptomatic, $0.04 \pm 0.007$ $\mu \mathrm{m}^{-1}$, terminal, $0.007 \pm 0.003 \mu \mathrm{m}^{-1}$; symptomatic vs presymp-

A
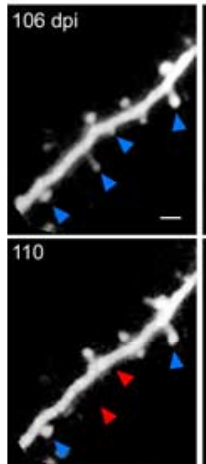

114

128

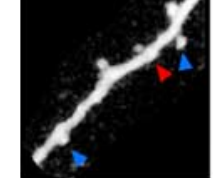

118
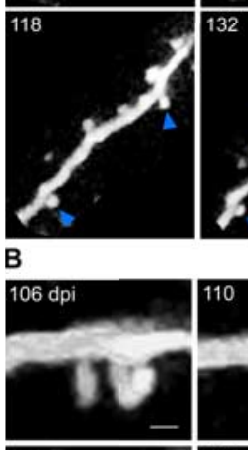
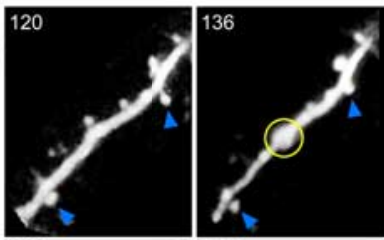

C

124
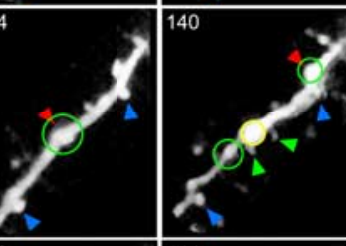

144

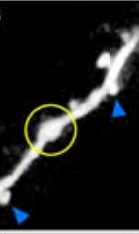

144
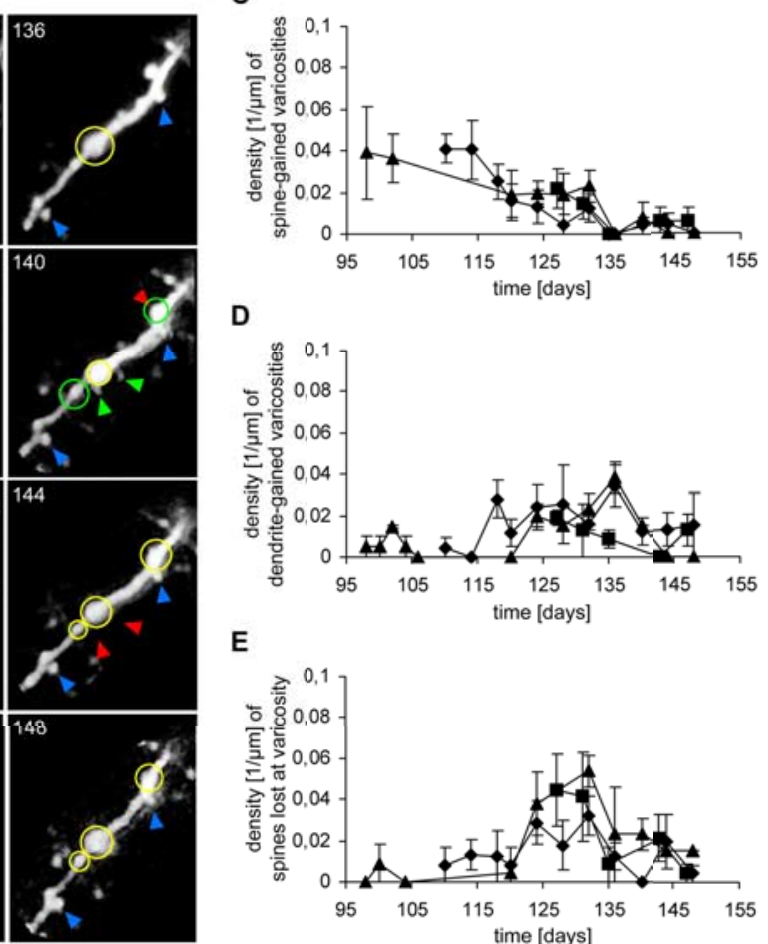

D

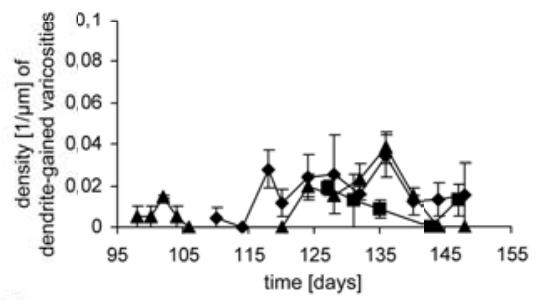

E
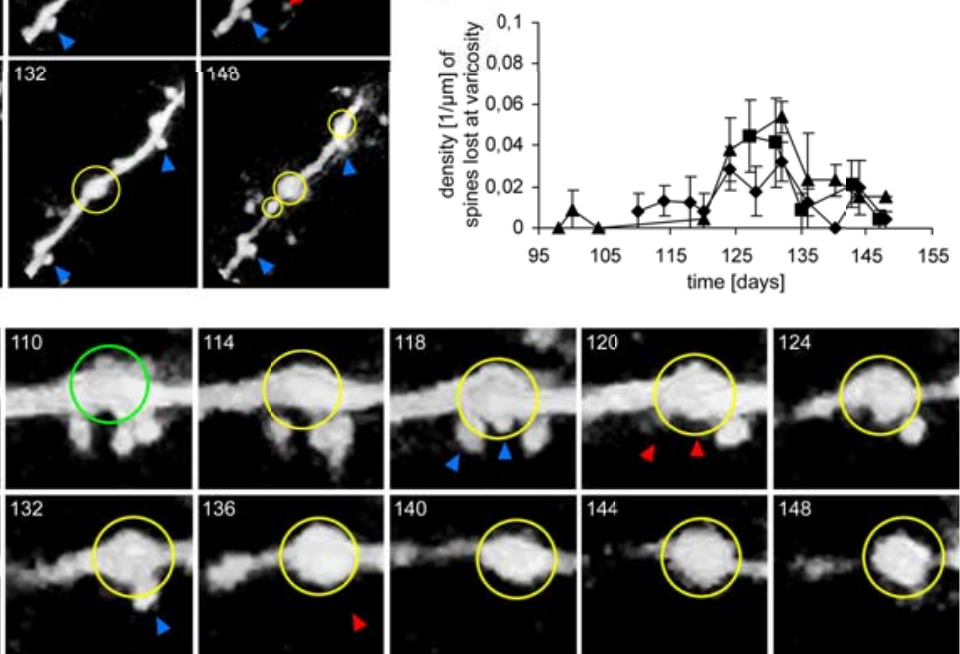

Figure 5. Dendritic varicosities predominantly gained at spines during the presymptomatic phase of prion disease subsequently loose adjacent spines during the symptomatic phase. $\boldsymbol{A}$, Representative time series of a scrapie-infected YFP-H mouse. green circles; persistent, yellow circles) mainly appeared at dendritic sites where spines protrude. Subsequently, a large number of spines was lost (red arrowheads) at gained or persistent varicosities. Rarely, new spines (green arrowheads) were gained at spine-gained density of varicosities in scrapie-infected mice. The density of spine-gained varicosities started at high values during the presymptomatic phase of the disease and decreased to nearly zero during the terminal phase (after $135 \mathrm{dpi}$ ). $\boldsymbol{D}$ Time course of the average dendrite-gained density varicosities in scrapie-infected mice. The density of dendrite-gained varicos$120 \mathrm{dpi}$ ). $\boldsymbol{E}$, Time course of the mean varicosity-lost spine density of scrapie-infected YFP-H mice. Spine loss at varicosities is infrequent during the presymptomatic phase of disease. The density of spines lost at varicosities raised throughout the symptomatic phase of the disease, reaching a peak $\sim 130 \mathrm{dpi}$, and decreased until the end of imaging period. $\boldsymbol{C}-\boldsymbol{E}$, Each line represents an animal and symbols indicate imaging days. Scale bars: $\boldsymbol{A}, 2 \mu \mathrm{m} ; \boldsymbol{B}, 1 \mu \mathrm{m}$.

tomatic, $p=5.0 \times 10^{-3}$; symptomatic vs terminal, $p=5.0 \times 10^{-4}$; $n=3$ animals). During the symptomatic phase, $59.6 \pm 6.3 \%$ of all spines were lost at varicosities. These results indicate that during the presymptomatic phase of prion disease, a substantial amount of varicosities emerge at dendritic sites, from where spines protrude. Subsequently, spines are eliminated at dendritic sites where varicosities previously appeared.

\section{Discussion}

To investigate dendrite and spine structural plasticity during a neurodegenerative disease, we used mice infected with scrapie prions as a model. Spine loss progressed slowly with kinetics of 
Table 1. Transient and persistent spines

\begin{tabular}{|c|c|c|c|c|c|c|}
\hline & \multicolumn{3}{|l|}{ Control (d) } & \multicolumn{3}{|c|}{ Scrapie-infected (dpi) } \\
\hline & 8 & 20 & 46 & 110 & 124 & 144 \\
\hline \multicolumn{7}{|l|}{ Persistent spine } \\
\hline Density $\left(\mu \mathrm{m}^{-1}\right)$ & $0.31 \pm 0.02$ & $0.32 \pm 0.02$ & $0.33 \pm 0.02$ & $0.21 \pm 0.03$ & $0.13 \pm 0.02$ & $0.03 \pm 0.01$ \\
\hline Fraction (\%) & $82.7 \pm 4.5$ & $82.0 \pm 5.9$ & $83.9 \pm 5.1$ & $93.0 \pm 2.0$ & $82.2 \pm 3.6$ & $65.3 \pm 8.4$ \\
\hline \multicolumn{7}{|l|}{ Transient spine } \\
\hline Density $\left(\mu \mathrm{m}^{-1}\right)$ & $0.06 \pm 0.02$ & $0.05 \pm 0.02$ & $0.05 \pm 0.02$ & $0.02 \pm 0.007$ & $0.03 \pm 0.008$ & $0.02 \pm 0.006$ \\
\hline Fraction (\%) & $17.3 \pm 4.6$ & $18.0 \pm 5.9$ & $16.1 \pm 5.1$ & $7.0 \pm 2.0$ & $17.8 \pm 3.6$ & $34.7 \pm 10.1$ \\
\hline
\end{tabular}

$5.9 \pm 0.5$ spines $/ \mathrm{mm}$ per day from the presymptomatic to the terminal phase of the disease. Analyzing the fate of transient and persistent spines in the somatosensory cortex revealed that preferentially persistent spines were lost, whereas the fraction of transient spines remained unchanged. At the dendrites, local dilatations, called varicosities, emerged as early as during the presymptomatic phase of the disease. They predominantly appeared at locations where spines protruded from the dendrite. Subsequently, spines were lost at those sites. In conclusion, our data indicate that intact neuronal circuits, represented by persistent spines, are progressively eliminated during prion disease. Loss of persistent spines might represent the structural correlate of cognitive decline and neurological symptoms.

\section{Slow progression of spine loss}

How does spine loss progress throughout a neurodegenerative disease like prion disease? Does it merely reflect the degeneration of synaptic inputs after cell death of the presynaptic neuron or is there any evidence that the disease process emanates from degenerating dendrites or synaptic spines? The current investigation revealed that structural changes of spine addition and elimination occurred over timescales of days $(5.9 \pm 0.5$ spines $/ \mathrm{mm}$ per day) (Fig. 3D), as has been shown for spines during development and adulthood (Holtmaat et al., 2005). Interestingly, spine loss was rarely found to be accompanied by a complete disappearance of the neurite. The fact that spine loss progressed slowly discourages the hypothesis that spines disappear as a consequence of nerve cell apoptosis and dendritic destruction. The presented data rather favors the hypothesis that nerve cell death represents the result of complete loss of synaptic input (BouzamondoBernstein et al., 2004).

Analysis of the dTORs of spines revealed that mice infected with scrapie prions show significantly higher dTORs than control mice (Fig. 3E). This means that diseased animals exhibit a higher rate of neuronal circuit rewiring compared with control mice. More synapses are formed and eliminated, but which process prevails: spine formation or elimination? Prion disease being a progressive neurodegenerative disease, one would expect spine loss to be more pronounced. Indeed, the fraction of lost spines exceeded the fraction of gained spines throughout the examination period (Figs. $3 F, G$ ). Moreover, the fraction of lost spines substantially increased from 135 dpi until the terminal phase (Fig. 3G). Unexpectedly, the fraction of gained spines was also found to be elevated from $120 \mathrm{dpi}$ to $140 \mathrm{dpi}$ (Fig. $3 F$ ). This period falls into the symptomatic phase, when neurological symptoms become manifested. During this critical period, enhanced spine gain might represent a compensatory reaction to increasing spine loss. Remarkably, mechanisms of spine formation seem to be unaffected during prion disease, because new spines emanated even during the symptomatic phase of the disease. This suggests that neurons are able to mount a compensatory reaction even in the hostile environment of $\mathrm{PrP}^{\mathrm{Sc}}$ accumu- lation. Further, changes on the synaptic level reflected by increased dTORs might be responsible for the induction of manifested neurological symptoms.

\section{Preferential loss of persistent spines}

Transient and persistent spines represent two independent groups of spines in the cortex of mice (Holtmaat et al., 2006; Knott et al., 2006). Only a fraction of transient spines forms functional synapses, whereas practically all persistent spines contact presynaptic boutons (Knott et al., 2006). Experience-dependent structural plasticity changes of spines after whisker trimming are represented by the elimination of formerly persistent spines and the emergence of new persistent spines, implicating that profound rewiring of neuronal circuits takes place (Holtmaat et al., 2006). We found that preferentially persistent spines were lost during prion disease, whereas the density of transient spines remained unchanged from the beginning to the end of the examination period (Table 1). Persistent spines represent intact synapses in the brain, which are stable for months or even throughout a lifetime (Holtmaat et al., 2005). Selective elimination of persistent spines means that previously existing neuronal circuits are destroyed during neurodegeneration. A lost persistent spine might represent the smallest degenerating structural unit responsible for the onset of neurological symptoms emerging during prion disease.

\section{Varicosities: cause of spine loss?}

Spine loss during prion disease was found to be accompanied by neuritic swellings called varicosities. Varicosities have already been described in previous studies on scrapie-infected rodents and in material from patients with Creutzfeldt-Jakob disease (Landis et al., 1981; Ferrer et al., 1981; Hogan et al., 1987; Jeffrey et al., 1997; Belichenko et al., 2000; Brown et al., 2001; Ishikura et al., 2005). Dendritic varicosities probably represent the cellular equivalent of vacuolar degeneration of the neuropil, characteristic for all transmissible spongiform encephalopathies. Varicosities have also been described in a variety of other progressive neurodegenerative diseases including Huntington's disease (Sotrel et al., 1993), frontal lobe dementia, and motor neuron disease (Ferrer et al., 1991), as well as Alzheimer's disease. Those varicosities have to be differentiated from hydropic varicosities shown to occur in acute neuronal damage like acute excitotoxicity caused by anoxia/ischemia (Park et al., 1996; Akulinin et al., 2004) or epilepsy (Belichenko and Dahlstrom, 1995). They are supposed to be the consequence of loss of isotonicity and acute swelling.

Here, we analyzed the time course of the density of varicosities in scrapie-infected mice for the first time. A total of $61 \pm 5 \%$ of varicosities emerged early during the presymptomatic phase of prion disease, reaching plateau values at 124 dpi (Fig. 4B). Gained varicosities persisted in $90 \pm 2.7 \%$ off all cases, implying that these structures are highly stable. Interestingly, the emer- 
gence of varicosities had no direct effect on the degeneration of dendrites, because in the majority of cases the dendrite, even packed with multiple neighboring varicosities, survived until the end of the examination period.

Correlating the emergence of varicosities with the elimination of spines, we found that varicosities predominantly occurred at dendritic sites where spines emanated. Of all gained varicosities during the symptomatic phase, $75 \pm 6 \%$ were spine-gained varicosities. The predominant gain of varicosities at spine sites was significantly different from the random case. Moreover, during the symptomatic phase of prion disease, $59.6 \pm 6.3 \%$ of spines were lost at varicosities, which may indicate that varicosities actually cause spine loss (Fig. $5 E$ ). The temporal and spatial coincidence between varicosity emergence and spine loss argues for a causative relationship and indicates that the part of the dendrite from which the spines protrude may be especially vulnerable. Currently, we do not know how the scrapie infection induces dendritic varicosities. One possible link may be the known association of $\operatorname{PrP}^{\mathrm{Sc}}$ with detergent-resistant cholesterol-sphingomyelin-enriched membrane domains (DRMs) (Galvan et al., 2005), which is believed to play a crucial role in the conversion of $\operatorname{PrP}^{\mathrm{C}}$ into $\mathrm{PrP}^{\text {res }}$ (Russelakis-Carneiro et al., 2004; Sandberg and Low, 2005). Scrapie infection is known to trigger the accumulation of $\mathrm{PrP}^{\mathrm{Sc}}$ in DRMs of retinas and optic nerves throughout early stages of the disease before the occurrence of neuronal cell death (Russelakis-Carneiro et al., 2004). Because blocking the function of DRMs by reducing the levels of cholesterol or sphingomyelin in cultured neurons is known to induce the formation of varicosities and the elimination of synaptic spines (Hering et al., 2003), it may be tempting to speculate that the occurrence of varicosities in scrapie may be related to the accumulation of $\mathrm{PrP}^{\mathrm{Sc}}$ in DRMs. In support of this hypothesis, cDNA microarray studies identified several differentially expressed genes related to cholesterol synthesis during the presymptomatic phase of prion disease (Xiang et al., 2007; Skinner et al., 2006). Additional studies will have to prove whether alterations in the cholesterol synthesis or DRM function, because of $\operatorname{PrP}^{\mathrm{Sc}}$ accumulation, represents the primary cause of varicosity emergence and subsequent spine loss in prion disease.

\section{References}

Akulinin VA, Semchenko VV, Stepanov SS, Belichenko PV (2004) Structural changes in the dendritic spines of pyramidal neurons in layer III of the sensorimotor cortex of the rat cerebral cortex in the late post-ischemic period. Neurosci Behav Physiol 34:221-227.

Belichenko PV, Dahlstrom A (1995) Studies on the 3-dimensional architecture of dendritic spines and varicosities in human cortex by confocal laser scanning microscopy and Lucifer yellow microinjections. J Neurosci Methods 57:55-61.

Belichenko PV, Brown D, Jeffrey M, Fraser JR (2000) Dendritic and synaptic alterations of hippocampal pyramidal neurones in scrapie-infected mice. Neuropathol Appl Neurobiol 26:143-149.

Bouzamondo-Bernstein E, Hopkins SD, Spilman P, Uyehara-Lock J, Deering C, Safar J, Prusiner SB, Ralston III HJ, DeArmond SJ (2004) The neurodegeneration sequence in prion diseases: evidence from functional, morphological and ultrastructural studies of the GABAergic system. J Neuropathol Exp Neurol 63:882-899.

Brown D, Belichenko P, Sales J, Jeffrey M, Fraser JR (2001) Early loss of dendritic spines in murine scrapie revealed by confocal analysis. NeuroReport 12:179-183.

Cunningham C, Deacon R, Wells H, Boche D, Waters S, Diniz CP, Scott H, Rawlins JN, Perry VH (2003) Synaptic changes characterize early behavioural signs in the ME7 model of murine prion disease. Eur J Neurosci $17: 2147-2155$.

Engert F, Bonhoeffer T (1999) Dendritic spine changes associated with hippocampal long-term synaptic plasticity. Nature 399:66-70.
Feng G, Mellor RH, Bernstein M, Keller-Peck C, Nguyen QT, Wallace M, Nerbonne JM, Lichtman JW, Sanes JR (2000) Imaging neuronal subsets in transgenic mice expressing multiple spectral variants of GFP. Neuron 28:41-51.

Ferrer I, Costa F, Grau Veciana JM (1981) Creutzfeldt-Jacob disease: a golgi study. Neuropathol Appl Neurobiol 7:237-242.

Ferrer I, Roig C, Espino A, Peiro G, Matias Guiu X (1991) Dementia of frontal lobe type and motor neuron disease. A Golgi study of the frontal cortex. J Neurol Neurosurg Psychiatry 54:932-934.

Fiala JC, Spacek J, Harris KM (2002) Dendritic spine pathology: cause or consequence of neurological disorders? Brain Res Brain Res Rev 39:29-54.

Galvan C, Camoletto PG, Dotti CG, Aguzzi A, Ledesma MD (2005) Proper axonal distribution of $\operatorname{Pr} \mathrm{P}(\mathrm{C})$ depends on cholesterol-sphingomyelinenriched membrane domains and is developmentally regulated in hippocampal neurons. Mol Cell Neurosci 30:304-315.

Grutzendler J, Kasthuri N, Gan WB (2002) Long-term dendritic spine stability in the adult cortex. Nature 420:812-816.

Harris KM, Stevens JK (1989) Dendritic spines of CAl pyramidal cells in the rat hippocampus: serial electron microscopy with reference to their biophysical characteristics. J Neurosci 9:2982-2997.

Hasbani MJ, Viquez NM, Goldberg MP (2001) NMDA receptors mediate hypoxic spine loss in cultured neurons. NeuroReport 12:2731-2735.

Hering H, Lin CC, Sheng M (2003) Lipid rafts in the maintenance of synapses, dendritic spines, and surface AMPA receptor stability. J Neurosci 23:3262-3271.

Hogan RN, Baringer JR, Prusiner SB (1981) Progressive retinal degeneration in scrapie-infected hamsters: a light and electron microscopical analysis. Lab Invest 44:34-42.

Hogan RN, Baringer JR, Prusiner SB (1987) Scrapie infection diminishes spines and increases varicosities of dendrites in hamsters: a quantitative Golgi analysis. J Neuropathol Exp Neurol 46:461-473.

Holtmaat A, Wilbrecht L, Knott GW, Welker E, Svoboda K (2006) Experience-dependent and cell-type-specific spine growth in the neocortex. Nature 441:979-983.

Holtmaat AJ, Trachtenberg JT, Wilbrecht L, Shepherd GM, Zhang X, Knott GW, Svoboda K (2005) Transient and persistent dendritic spines in the neocortex in vivo. Neuron 45:279-291.

Ishikura N, Clever JL, Bouzamondo-Bernstein E, Samayoa E, Prusiner SB, Huang EJ, DeArmond SJ (2005) Notch-1 activation and dendritic atrophy in prion disease. Proc Natl Acad Sci USA 102:886-891.

Jeffrey M, Goodsir CM, Bruce ME, McBride PA, Fraser JR (1997) In vivo toxicity of prion protein in murine scrapie: ultrastructural and immunogold studies. Neuropathol Appl Neurobiol 23:93-101.

Jeffrey M, Halliday WG, Bell J, Johnston AR, MacLeod NK, Ingham C, Sayers AR, Brown DA, Fraser JR (2000) Synapse loss associated with abnormal PrP precedes neuronal degeneration in the scrapie-infected murine hippocampus. Neuropathol Appl Neurobiol 26:41-54.

Jiang MH, Lee CL, Smith KL, Swann JW (1998) Spine loss and other persistent alterations of hippocampal pyramidal cell dendrites in a model of early-onset epilepsy. J Neurosci 18:8356-8368.

Johnston AR, Black C, Fraser J, MacLeod N (1997) Scrapie infection alters the membrane and synaptic properties of mouse hippocampal CA1 pyramidal neurones. J Physiol (Lond) 500:1-15.

Kharazia VN, Weinberg RJ (1999) Immunogold localization of AMPA and NMDA receptors in somatic sensory cortex of albino rat. J Comp Neurol 412:292-302.

Knott GW, Holtmaat A, Wilbrecht L, Welker E, Svoboda K (2006) Spine growth precedes synapse formation in the adult neocortex in vivo. Nat Neurosci 9:1117-1124.

Landis DM, Williams RS, Masters CL (1981) Golgi and electronmicroscopic studies of spongiform encephalopathy. Neurology 31:538-549.

Majewska AK, Newton JR, Sur M (2006) Remodeling of synaptic structure in sensory cortical areas in vivo. J Neurosci 26:3021-3029.

Nagerl UV, Eberhorn N, Cambridge SB, Bonhoeffer T (2004) Bidirectional activity-dependent morphological plasticity in hippocampal neurons. Neuron 44:759-767.

Nusser Z, Lujan R, Laube G, Roberts JD, Molnar E, Somogyi P (1998) Cell type and pathway dependence of synaptic AMPA receptor number and variability in the hippocampus. Neuron 21:545-559.

Okamoto K, Nagai T, Miyawaki A, Hayashi Y (2004) Rapid and persistent 
modulation of actin dynamics regulates postsynaptic reorganization underlying bidirectional plasticity. Nat Neurosci 7:1104-1112.

Park JS, Bateman MC, Goldberg MP (1996) Rapid alterations in dendrite morphology during sublethal hypoxia or glutamate receptor activation. Neurobiol Disease 3:215-227.

Patt S, Gertz HJ, Gerhard L, Cervosnavarro J (1991) Pathological changes in dendrites of substantia-nigra neurons in Parkinson's disease: a Golgi study. Histol Histopathol 6:373-380.

Prusiner SB (1998) Prions. Proc Natl Acad Sci USA 95:13363-13383.

Russelakis-Carneiro M, Hetz C, Maundrell K, Soto C (2004) Prion replication alters the distribution of synaptophysin and caveolin 1 in neuronal lipid rafts. Am J Pathol 165:1839-1848.

Sandberg MK, Low P (2005) Altered interaction and expression of proteins involved in neurosecretion in scrapie-infected GT1-1 cells. J Biol Chem 280:1264-1271.

Selkoe DJ (2002) Alzheimer's disease is a synaptic failure. Science 298:789-791.

Skinner PJ, Abbassi H, Chesebro B, Race RE, Reilly C, Haase AT (2006) Gene expression alterations in brains of mice infected with three strains of scrapie. BMC Genomics 7:114.

Sotrel A, Williams RS, Kaufmann WE, Myers RH (1993) Evidence for neuronal degeneration and dendritic plasticity in cortical pyramidal neurons of Huntington's disease: a quantitative Golgi study. Neurology 43:2088-2096.

Spires TL, Hyman BT (2004) Neuronal structure is altered by amyloid plaques. Rev Neurosci 15:267-278.

Spires TL, Meyer-Luehmann M, Stern EA, McLean PJ, Skoch J, Nguyen PT, Bacskai BJ, Hyman BT (2005) Dendritic spine abnormalities in amyloid precursor protein transgenic mice demonstrated by gene transfer and intravital multiphoton microscopy. J Neurosci 25:7278-7287.
Tada T, Sheng M (2006) Molecular mechanisms of dendritic spine morphogenesis. Curr Opin Neurobiol 16:95-101.

Takumi Y, Ramirez-Leon V, Laake P, Rinvik E, Ottersen OP (1999) Different modes of expression of AMPA and NMDA receptors in hippocampal synapses. Nat Neurosci 2:618-624.

Trachtenberg JT, Chen BE, Knott GW, Feng G, Sanes JR, Welker E, Svoboda $\mathrm{K}$ (2002) Long-term in vivo imaging of experience-dependent synaptic plasticity in adult cortex. Nature 420:788-794.

Tsai J, Grutzendler J, Duff K, Gan WB (2004) Fibrillar amyloid deposition leads to local synaptic abnormalities and breakage of neuronal branches. Nat Neurosci 7:1181-1183.

Xiang W, Hummel M, Mitteregger G, Kohlmannsperger V, Nolting S, Hamann GF, Kretzschmar HA (2007) Transcriptome analysis reveals altered cholesterol metabolism during the neurodegeneration in mouse scrapie model. J Neurochem, in press.

Yoshiyama Y, Higuchi M, Zhang B, Huang SM, Iwata N, Saido TC, Maeda J, Suhara T, Trojanowski JQ, Lee VM (2007) Synapse loss and microglial activation precede tangles in a P301S tauopathy mouse model. Neuron 53:337-351.

Zhang S, Boyd J, Delaney K, Murphy TH (2005) Rapid reversible changes in dendritic spine structure in vivo gated by the degree of ischemia. J Neurosci 25:5333-5338.

Zhou Q, Homma KJ, Poo MM (2004) Shrinkage of dendritic spines associated with long-term depression of hippocampal synapses. Neuron 44:749-757.

Zuo Y, Lin A, Chang P, Gan WB (2005) Development of long-term dendritic spine stability in diverse regions of cerebral cortex. Neuron 46:181-189. 